\title{
Neuer GPR-Vorstand gewählt
}

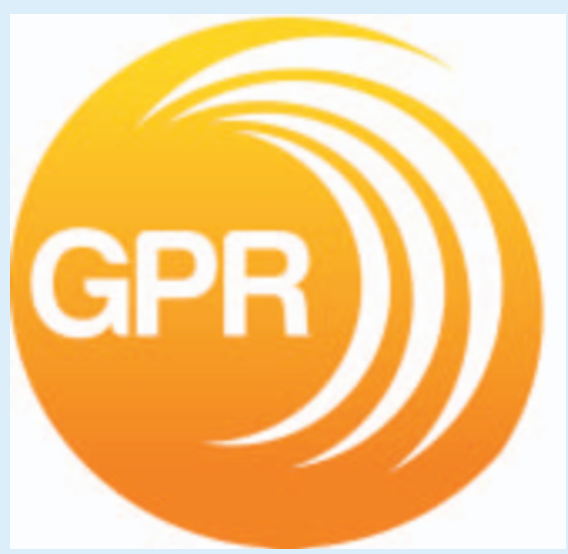

Im Rahmen der 58. Jahrestagung der Gesellschaft für Pädiatrische Radiologie, die vom 23.-25. September als Hybridkongress digital und in Graz stattgefunden hat, wurde turnusgemäß ein neuer Vorstand gewählt.

Neue Präsidentin ist PD Dr. Thekla von Kalle vom Klinikum Stuttgart. Das Amt der Vizepräsidentin übernimmt Prof. Dr. Diane Renz von der Medizinischen Hochschule Hannover. Zweite Beisitzerin ist Dr. Stephanie Spieth vom Universitätsklinikum

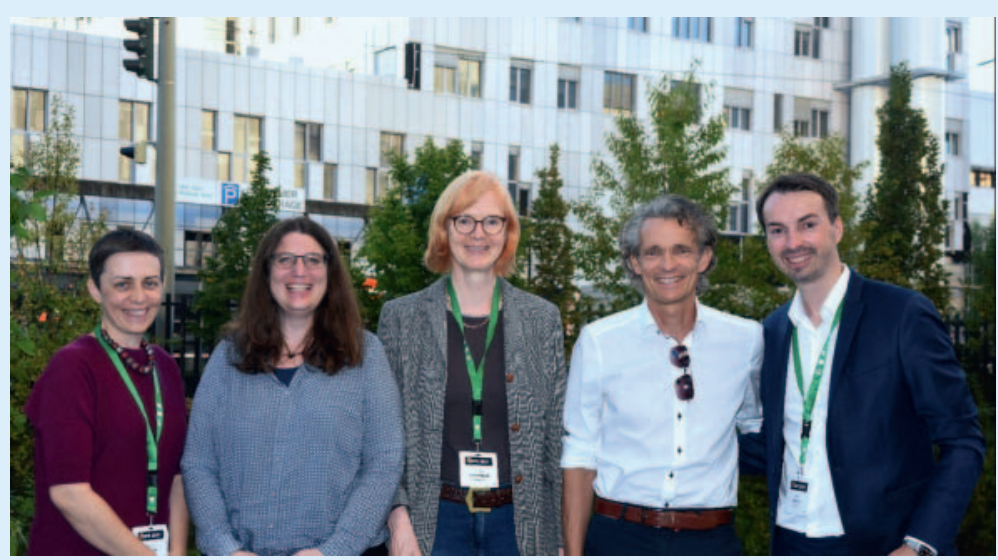

Der neue Vorstand der GPR ab 2022 (v. I. n. r.): Prof. Dr. Janina Patsch (Wien), Prof. Dr. Diane Renz (Hannover), PD Dr. Thekla von Kalle (Stuttgart), Dr. Dirk Klee (Düsseldorf), Dr. Mario Scala (Linz). Leider nicht vor Ort in Graz sein konnten Dr. Stephanie Spieth (Dresden) und Dr. Maren Balks (Lübeck). @ Alexander Kolli

Dresden. In ihrem Amt bestätigt wurden Schriftführer und Schatzmeister Dr. Dirk Klee vom Universitätsklinikum Düsseldorf sowie Erste Beisitzerin Prof. Dr. Janina Patsch von der Medizinischen Universität Wien. Auch die beiden Vertreter der Jungen Kinderradiologie, Dr. Maren Balks vom Universitätsklinikum Lübeck und Dr. Mario Scala vom Universitätsklinikum Linz, wurden in ihren Ämtern bestätigt. Der neue Vorstand nimmt seine Arbeit ab dem kommenden Jahr 2022 auf.

Prof. Dr. Hans-Joachim Mentzel und Dr. Gabriele Hahn scheiden 2022 aus dem Vorstand aus. Wir danken beiden schon jetzt für ihren großartigen Einsatz für die GPR. 